\title{
References
}

1 Kaplan BM. Sick sinus syndrome. Arch Intern Mcd 1978;138:28.

2 Macleod AA, Jewitt DE. Role of 24-hour ambulatory electrocardiographic monitoring in a general hospital. $\mathrm{Br} M e d \mathcal{F} 1978$; i:1197-9.

${ }^{3}$ Johansson BW. Complete heart block. Acta Med Scand 1966;180: suppl $451 ; 1$.

${ }^{4}$ Ferrer MI. The sick sinus syndrome: its status after ten years. Chest $1977 ; 72: 554-5$.

5 Nolan SP, Crampton RS, McGuire LB, McGann RC, Holz HC, Muller WH. Factors influencing survival of patients with permanent cardiac pacemakers. Ann Surg 1976;185:122-7.

${ }^{6}$ Krishnaswami V, Geraci AR. Permanent pacing in disorders of sinus node function. Am Heart $₹ 1975 ; 89: 579-85$.

7 Wohl AJ, Laborde J, Atkins JM, Blomqvist CG, Mullins CB. Prognosis of patients permanently paced for sick sinus syndrome. Arch Intern Med 1976;136:406-8.

${ }^{8}$ Gould L, Reddy CVR, Becker WH. The sick sinus syndrome: a study of 50 cases. F Electrocardiol 1978;11:11-14.

${ }^{\circ}$ Gann D, Tolentino A, Samet P. Electrophysiologic evaluation of elderly patients with sinus bradycardia. Ann Intern Med 1979;90:24-9.

10 Shaw DB, Eraut D. Prevalence and morbidity of heart block in Devon. Br Med F 1970;i:144-7.
11 Shaw DB, Kekwick CA. Potential candidates for pacemakers (survey of heart block and sinoatrial disorder; sick sinus syndrome). $\mathrm{Br}$ Heart $\mathcal{F}$ 1978;40:99-105.

12 Cutler SJ, Ederer F. Maximum utilisation of the life-table method in analysing survival. $f$ Chronic Dis 1958;11:699-712.

13 Cox DR. Regression models and life tables. $\mathscr{F} R$ Statist Soc B 1972;34:187220.

14 Peto $R$, Peto J. Asymptotically efficient rank invariant test procedures. f $R$ Statist Soc $A$ 1972;135:185-206.

15 Registrar General. Decennial supplement for England and Wales: Lifetables. London: HMSO, 1968.

16 Eraut D, Shaw DB. Sinus bradycardia. Br Heart $\mathcal{f} 1971$;33:742-9.

17 Ferrer MI. The sick sinus syndrome. Circulation 1973;47:635-41.

${ }^{18}$ Lien WP, Lee YS, Chang FZ, Lee SY, Chen CM, Tsai HC. The sick sinus syndrome (natural history of dysfunction of the sinoatrial node). Chest 1977;72:628-34.

19 Hartel G, Talvensaari T. Treatment of sinoatrial syndrome with permanent cardiac pacing in 90 patients. Acta Med Scand 1975;198:341-7.

(Accepted 12 October 1979)

\section{Postprandial gall-bladder emptying in patients with gall stones}

\author{
D P MAUDGAL, R M KUPFER，P L ZENTLER-MUNRO， T C NORTHFIELD
}

\section{Summary and conclusions}

Gall-bladder emptying in response to a standard meal was assessed in 34 patients with radiolucent gall stones and 34 matched controls. Percentage gall-bladder emptying, derived from volume measurements made on standardised oral cholecystography, was significantly higher at 15 minutes in the patients than the controls (mean \pm SE of mean $38.0 \pm 3.7 \% \quad v \quad 28.0 \pm 3.8 \%$ ). This difference was maintained at 30 and 60 minutes.

It is concluded that postprandial gall-bladder emptying is increased in patients with cholesterol gall stones, and that this may be the cause of the small bile-acid pool found in these patients.

\section{Introduction}

Patients with cholesterol gall stones have fasting gall-bladder bile that is supersaturated with cholesterol ${ }^{1}$ and a reduced bile-acid (BA) pool size. ${ }^{2}$ The cause of this small BA pool is unknown. An inverse relation exists between the size and recycling frequency of the BA pool. ${ }^{3}$ Thus an increased recycling frequency might cause a small pool by feedback inhibition of the synthesis of BA. Since the gall bladder is the storage organ for the BA pool, its emptying after a meal may determine the recycling frequency and hence the size of the pool.

We therefore tested the hypothesis that postprandial gallbladder emptying is increased in patients with gall stones by

\footnotetext{
Norman Tanner Gastroenterology Unit, St James's Hospital, and Department of Medicine, St George's Hospital Medical School, London SW17 ORE

D P MAUDGAL, MRCP, senior medical registrar

R M KUPFER, MA, MRCP, research registrar

P L ZENTLER-MUNRO, MA, MRCP, research senior registrar

T C NORTHFIELD, MD, FRCP, consultant physician and senior lecturer
}

comparing the response to a standard meal in 34 such patients and 34 controls. To limit the study as far as possible to patients with cholesterol gall stones we included only those with radiolucent stones, since $80 \%$ of such stones contain over $70 \%$ cholesterol. ${ }^{4}$ We were careful to match the patients and controls in pairs for age, sex, obesity, and race because the prevalence of cholesterol gall stones is related to these factors ${ }^{56}$ and gallbladder emptying is affected by age and sex.?

\section{Patients and methods}

We studied 34 patients with radiolucent gall stones in a gall bladder that opacified on oral cholecystography. Patients with calcified gall stones and those whose gall stones occupied over half of the gallbladder volume were excluded. We also studied 34 control subjects with dyspeptic symptoms and an unequivocally normal cholecystogram. They were matched in pairs with the patients with gall stones for age (within 10 years), height $(10 \mathrm{~cm})$, body weight $(10 \mathrm{~kg})$, race, and sex. Ten of the pairs were men and 24 women. The mean age of the patients was 52 years and of the controls 53 years; the corresponding mean weights were $72 \mathrm{~kg}$ and $68 \mathrm{~kg}$, and the corresponding mean heights $167 \mathrm{~cm}$ and $164 \mathrm{~cm}$. Six patients and six controls were over $120 \%$ of their ideal body weight. Written informed consent was obtained from all subjects before they entered the study.

We assessed gall-bladder emptying by means of carefully standardised oral cholecystography. The subject was supine, and angulation over the $x$-ray film was adjusted by means of a wooden wedge to give an angle of $45^{\circ}$. The $x$-ray tube was adjusted to a distance of $100 \mathrm{~cm}$ from the plate. In premenopausal women cholecystography was carried out within 10 days after the onset of the menstrual cycle, thus eliminating differences in emptying during different phases of the menstrual cycle. ${ }^{8} X$-ray films were taken in the fasting state and 15 , 30 , and 60 minutes after a standard liquid test meal (Lundh), a pilot study having shown that maximum emptying always occurred within the first hour after the meal. The gall bladder was outlined on tracing paper. Area was measured by means of a grid system, and volume was calculated by the method described and validated by Silva. ${ }^{9}$ Both measurements were made by someone unaware of the diagnosis. Statistical analysis was carried out by using the Wilcoxon signed-rank test for paired samples. 


\section{Results}

Fasting gall-bladder volume (mean $\pm \mathrm{SE}$ of mean) was $78.9 \pm$ $6.2 \mathrm{~cm}^{3}$ in the patients with gall stones and $82 \cdot 3 \pm 6.0 \mathrm{~cm}^{3}$ in the controls (difference not significant; NS). Maximum emptying sometimes occurred before 60 minutes, and was followed by refilling. Cumulative emptying was calculated to take this into account. Figure 1 shows the cumulative emptying expressed as a percentage of the fasting volume. At 15 minutes the decrease in gall-bladder volume

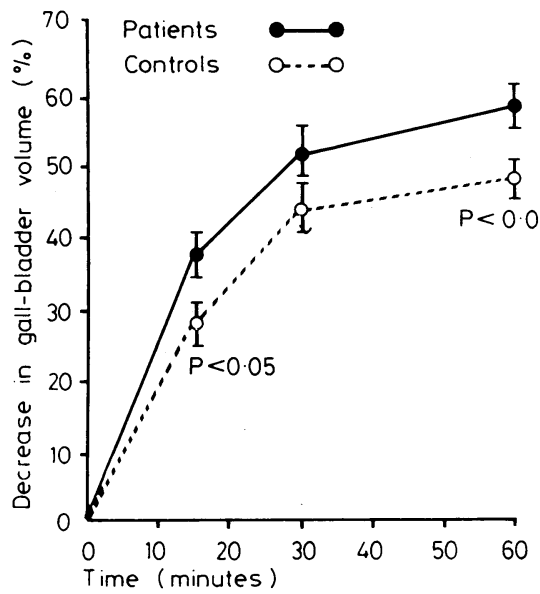

FIG 1-Cumulative gall-bladder emptying (mean $\pm \mathrm{SE}$ of mean) in patients with gall stones and controls at 15,30 , and 60 minutes after a standard meal.

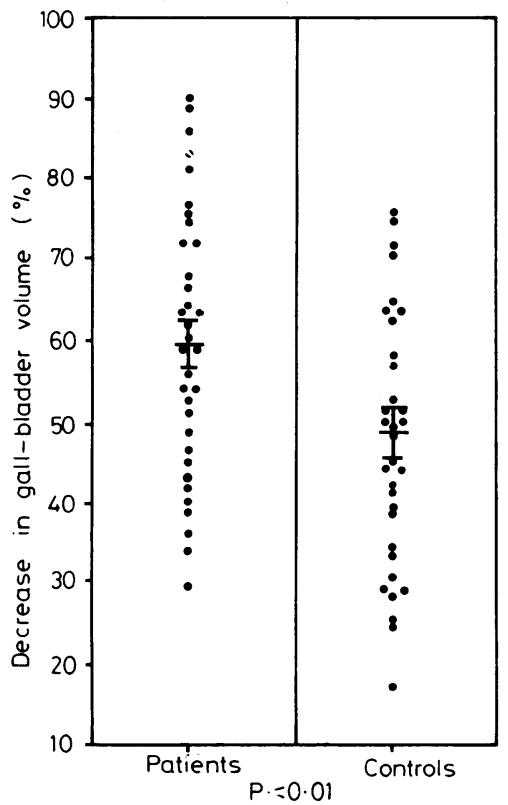

FIG 2-Cumulative gall-bladder emptying (mean $\pm \mathrm{SE}$ of mean) at 60 minutes in patients with gall stones and controls, showing individual data points.

was $38 \cdot 0 \pm 3 \cdot 7 \%$ in the patients and $28.0 \pm 3.8 \%$ in the controls $(\mathrm{p}<0.05)$; at 30 minutes it was $52.5 \pm 2.8 \%$ in the patients compared with $44 \cdot 2 \pm 3.0 \%$ in the controls (NS); and at 60 minutes $59 \cdot 3 \pm$ $3.2 \%$ in the patients compared with $48.5+2.7 \%$ in the controls $(\mathrm{p}<0.01)$. Figure 2 shows the individual data points for cumulative emptying at 60 minutes. When assessed by the alternative method based on area 60-minute cumulative emptying was $45.7 \pm 2.8 \%$ in the patients and $32 \cdot 7 \pm 2.4 \%$ in the controls $(\mathrm{p}<0.01)$. In the patients the results at 60 minutes increased by $5.0 \%$ when the area occupied by the gall stones was subtracted from the area measurement and by $2.5 \%$ when the volume occupied by the stones was subtracted from the volume measurement.
In seven normal subjects gall-bladder emptying was measured on two separate occasions six weeks apart. The mean difference between the two measurements was $4.0 \%$ when based on area and $8.0 \%$ when based on volume. There was a good correlation between the measurements of gall-bladder emptying based on area and those based on volume in 67 patients and controls $(r=0.93 ; p<0.001)$. Measurement of gall-bladder emptying was repeated in four patients after their gall stones had been completely dissolved and chenic acid treatment stopped. Mean gall-bladder emptying by volume in these four subjects was $50 \cdot 7 \pm 6.0 \%$ before dissolution and $58 \cdot 0 \pm 2 \cdot 7 \%$ after complete dissolution.

\section{Discussion}

The results of this study confirm our hypothesis that gallbladder emptying in response to food is greater in patients with cholesterol gall stones than in matched controls. This difference was fully established at 15 minutes and was maintained at 30 and 60 minutes. It was found with both methods of measurement. The results of repeat studies after complete dissolution make it unlikely that this difference is a secondary effect due to the presence of gall stones.

Our findings contrast with the report of van der Linden ${ }^{10}$ that patients with decreased gall-bladder emptying are more prone to develop gall stones in later life. Most of his subjects who subsequently developed gall stones were women, whereas most who did not, and thus acted as controls, were men. There was no matching for other factors such as weight and age. The women were not studied at a fixed point in the menstrual cycle; gall-bladder emptying is decreased in the second half of the cycle. ${ }^{8}$ We studied all our premenopausal subjects, both patients and controls, during the first 10 days of the menstrual cycle.

Increased gall-bladder emptying probably contributes to the decreased BA pool size reported in patients with gall stones. Gall-bladder emptying in our patients exceeded that in controls by a third at 15 minutes and by a fifth at 60 minutes, but values overlapped considerably at both times. This overlap would have been only slightly reduced if we had subtracted the volume occupied by the gall stones from our emptying measurements. By contrast, Vlahcevic et al reported little overlap in BA pool size. ${ }^{2}$ Their subjects were all male, and subsequent studies have shown greater overlap in pool size between female patients and controls. ${ }^{11}$ Our study included six patients and six controls more than $120 \%$ above ideal body weight. Obesity is associated with increased biliary cholesterol secretion, ${ }^{12}$ which is probably more important than changes in BA pool size in causing supersaturated bile in these patients.

We gratefully acknowledge the help given by the $x$-ray department at St James's Hospital. This study received financial support from Weddel Pharmaceuticals.

Requests for reprints should be addressed to Dr T C Northfield, Department of Medicine, St George's Hospital Medical School, London SW17 ORE.

\section{References}

${ }^{1}$ Admirand WH, Small DM. The physicochemical basis of cholesterol gallstone formation in man. $\mathcal{F}$ Clin Inv $1968 ; 47: 1043-52$

2 Vlahcevic ZR, Bell CC, Buhac I, Farrar JT, Swell L. Diminished bile acid pool size in patients with gallstones. Gastroenterology 1970;59: 165-73.

${ }^{3}$ Northfield TC, Hofman AF. Biliary lipid output during three meals and an overnight fast. I Relationship to bile acid pool size and cholesterol saturation of bile in gallstone and control subjects. Gut $1975 ; 16: 1-11$

${ }^{4}$ Bell GD, Dowling RH, Whitney B, Sutor DJ. The value of radiology in predicting gallstone type when selecting patients for medical treatment. Gut $1975 ; 16: 359-64$.

5 Thistle JL, Eckhert KL, Nensel RE, et al. Prevalence of gallbladder disease among Chippewa Indians. Mayo Clin Proc 1971;46:603-8.

${ }^{6}$ Zahor Z, Sterby NH, Kagan A, Vemera K, Vanecek R, Vicherd AM. Frequency of cholelithiasis in Prague and Malmo; an autopsy study. Scand $\mathcal{F}$ Gastroenterol 1974;9:3-7. 
7 Sachetti G, Mandelli V, Roncoroni L, Montanari C. Influence of sex and age on gallbladder emptying by a fatty meal in normal subjects. Am $\mathcal{F}$ Roentgenol 1973;119:40-5.

${ }^{8}$ Nilson S, Stattin S. Gallbladder emptying during the normal menstrual cycle. Acta Chir Scand 1967;133:648-52.

$\theta$ Silva GGE. A simple method of computing the volume of the human gallbladder. Radiology 1949;52:94-102.
10 Van der Linden W. Emptying of the human gallbladder and predisposition to gallstone formation. Tijdschr Gastroenterol 1974;17:121-8.

11 Pomare EN, Heaton KW. Bile salt metabolism in patients with gallstones in functioning gallbladders. Gut $1973 ; 14: 885-90$.

12 Bennion LJ, Grundy SM. Effects of obesity and caloric intake on biliary lipid metabolism in man. $\mathcal{F}$ Clin Invest 1975;56:996-1011.

\title{
Gall-bladder sensitivity to cholecystokinin in patients with gall stones
}

\author{
T C NORTHFIELD， R M KUPFER，D P MAUDGAL，P L ZENTLER-MUNRO，S T MELLER, \\ N W GARVIE, R MCCREADY
}

\section{Summary and conclusions}

Gall-bladder sensitivity to cholecystokinin (CCK) was determined by dynamic cholescintigraphy in 18 patients with radiolucent gall stones and 18 matched controls during an infusion of $\mathrm{CCK}$ in which the rate of infusion was increased. In 10 of the matched pairs the patient was more sensitive than the control, in one the control was more sensitive, and in seven no difference was detected $(p=0.012)$.

It is concluded that patients with cholesterol gall stones have increased gall-bladder sensitivity to CCK, and that this may be important in the pathogenesis of this disease.

\section{Introduction}

Altered gall-bladder function may be important in the pathogenesis of cholesterol gall stones. Postprandial gall-bladder emptying is increased in patients with cholesterol gall stones compared with matched controls. ${ }^{1}$ Gall-bladder emptying is initiated by cholecystokinin (CCK), which is released from the duodenal mucosa in response to food. The increased gallbladder emptying found in patients with gall stones is probably due either to an increase in serum CCK concentrations or to an increase in gall-bladder sensitivity to normal CCK concentrations. We have reported preliminary data obtained by means of a bioassay for CCK, which showed no significant difference in postprandial serum CCK concentrations between patients with gall stones and control subjects. ${ }^{2}$

The aim of the current study was to compare gall-bladder sensitivity to CCK in patients with gall stones and controls. We used a scintigraphic method to identify the onset of gallbladder contraction during an infusion of CCK in which the rate of infusion was increased.

\footnotetext{
Norman Tanner Gastroenterology Unit, St James's Hospital, and Department of Medicine, St George's Hospital Medical School, London SW17 ORE

T C NORTHFIELD, MD, FRCP, consultant physician and senior lectuerr R M KUPFER, MA, MRCP, research registrar

D P MAUDGAL, MRCP, senior medical registrar

P L ZENTLER-MUNRO, MA, MRCP, research senior registrar

Department of Nuclear Medicine, Royal Marsden Hospital, Sutton $S$ T MELLER, MRCP, senior registrar N W GARVIE, MRCP, senior registrar R MCCREADY, MSC, FRCR, consultant
}

\section{Patients and methods}

We studied 18 patients, all of whom had radiolucent gall stones in a gall bladder that opacified on oral cholecystography. Eighteen control subjects with dyspeptic symptoms and an unequivocally normal cholecystogram were matched with individual patients for height (within $10 \mathrm{~cm}$ ), weight (within $10 \mathrm{~kg}$ ), age (within 10 years), sex, and race. Thirteen of the pairs were women and five men. The mean age of the patients was 53 years and of the controls 54 years; the corresponding mean weights were $73 \mathrm{~kg}$ and $67 \mathrm{~kg}$, and the corresponding mean heights 165 and $163 \mathrm{~cm}$. We also studied four additional patients with gall stones, for whom no matched controls were available. All subjects gave written informed consent to the study.

Gall-bladder 'sensitivity to CCK was determined by dynamic cholescintigraphy using ${ }^{99 \mathrm{~m}}$ technetium-labelled $N$-(2,6-diethylphenylcarbamoylmethyl) iminodiacetate ( $\left.{ }^{99 \mathrm{~m}} \mathrm{Tc}-\mathrm{HIDA}\right)$. After an overnight fast $10 \mu \mathrm{Ci} 99 \mathrm{~m} \mathrm{Tc}-\mathrm{HIDA} / \mathrm{kg}$ was injected intravenously and the gall-bladder uptake of the radionuclide recorded by using a gamma camera linked to a small computer. Ninety minutes later, when gall-bladder activity had reached a steady state, an intravenous infusion of CCK (Karolinska) diluted in isotonic saline was started at an initial rate of $0.005 \mathrm{mU}$ (Ivy $\mathrm{dog}$ ) $/ \mathrm{kg} / \mathrm{min}$, followed by infusions of $0.01,0.03$, and $0.06 \mathrm{mU} / \mathrm{kg} / \mathrm{min}$. Because the half life of CCK is 2.5 minutes each CCK infusion was given for 12 minutes and followed by a six-minute saline infusion before the rate was increased.

Data were stored on magnetic disc for subsequent analysis. A region of interest corresponding to the gall bladder was identified and activity-time curves generated to identify the onset and rate of gall-bladder emptying. Gall-bladder sensitivity to CCK was defined as the threshold infusion rate causing a point of discontinuity on the activity-time curve that resulted in a $10 \%$ fall in activity before the infusion at the next rate was started (figure). The rate of gall-bladder

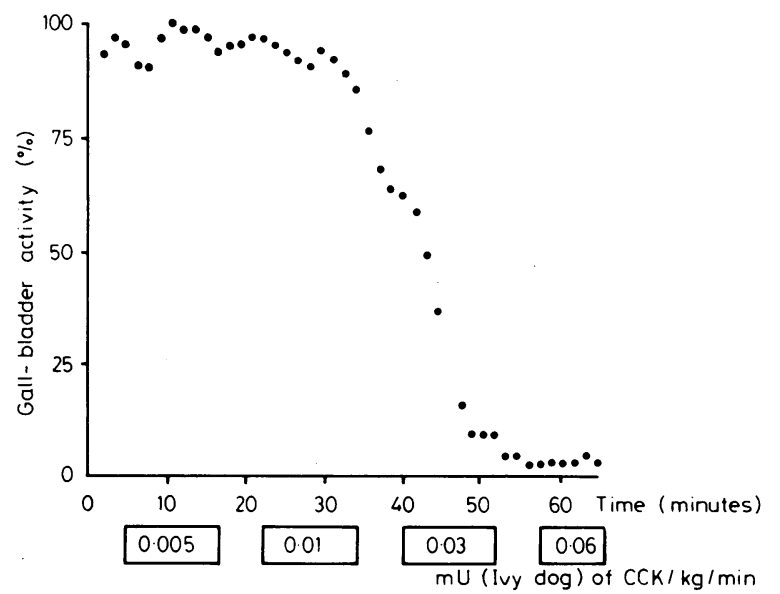

Tracing of gall-bladder radioactivity in one subject, showing gall-bladder contraction in response to a threshold infusion rate of $0.01 \mathrm{mU}$ (Ivy dog) of CCK/ $\mathrm{kg} / \mathrm{min}$ but no response to 0.005 $\mathrm{mU} / \mathrm{kg} / \mathrm{min}$. 